\title{
Violencia hacia las mujeres en el lenguaje: género gramatical, estereotipos y narrativas
}

\author{
Violence against women in the language: \\ grammatical gender, stereotypes and narratives \\ ANNA MARÍA FERNÁNDEZ PONCELA \\ Universidad Autónoma Metropolitana, Ciudad de México \\ ORCID 0000-0003-3080-212X \\ fpam1721@correo.xoc.uam.mx
}

\section{RESUMEN}

El lenguaje comunica, el uso del lenguaje crea afecto y acerca, también hiere y aleja. Aquí se explora y describe de manera general el desprecio y la violencia hacia las mujeres en varios ámbitos del lenguaje en español, género gramatical, léxico y algunas narrativas populares, canciones, refranes, chistes y acertijos. En todos ellos se observa la violencia de género, el androcentrismo y el sexismo lingüístico, parte de la violencia cultural según la lógica de la dominación que condiciona las formas de vivir en sociedad.

Palabras clave: violencia; mujeres; género gramatical; léxico; narrativas.

\begin{abstract}
Language communicates, the use of the language creates affection and approaches, also hurts and moves away. Here it explores and describes in general contempt and violence against women in several areas of language in spanish, lexical, grammatical gender, and some popular narratives, songs, sayings, jokes and riddles. All of them shows the androcentrism and linguistic sexism in the history and today, gender-based violence, part of cultural violence according to the logic of domination which determines the ways of living in society.
\end{abstract}

Keywords: violence; women; grammatical gender; lexicon; narratives.

\section{PRESENTACIÓN E INTRODUCCIÓN}

La mujer no puede emplear las estructuras lingüísticas dominadas por el hombre para decir lo que quisiera decir, para referir su visión del mundo. Sus declaraciones son deformadas, sofocadas, silenciadas (Moore, 1991:16). 
La diferencia sexual existe en el mundo, desde los cuerpos distintos o el sexo biológico hasta los modelos culturales diversos o la identidad genérica social e históricamente construida. No vamos a entrar aquí en la discusión o reflexión entre sexos y géneros, sí nos interesa proponer la revisión de cómo la diferencia sexual y su correspondiente construcción genérica hace que las personas difieran a la hora de la experiencia sensible del mundo, entre otras cosas, y cómo y también, representen ese mundo simbólicamente y de manera diversa a través del lenguaje.

Cómo el lenguaje representa la diferencia sexual, hay quien se pregunta. Aquí más bien nos interrogamos en torno a cómo usamos el lenguaje para representar, ocultar, sobrevalorar o denigrar a las mujeres, todo ello desde una perspectiva de género. Por supuesto, también se utiliza el lenguaje en ocasiones de manera respetuosa, valorativa y equitativa, eso no hay que olvidarlo. Sin embargo, hay una tendencia al señalamiento y desprecio de la otra, y esto tiene lugar en ámbitos distintos, desde la morfología y el género gramatical hasta el léxico, la semántica y los estereotipos de género, pasando por narrativas tradicionales y populares como refranes, acertijos, chistes y canciones, como se verá a lo largo de estas páginas.

El objetivo de este trabajo es precisamente revisar el lenguaje violento hacia las mujeres de manera específica en los espacios y medios anteriores, un lenguaje que produce y reproduce la violencia cultural, simbólica, psicológica y lingüística, todas ellas fincadas en la violencia estructural y la lógica de la dominación en las relaciones de poder que condicionan formas de pensar, sentir, hablar y vivir, divide a hombres y mujeres, otorga valor distinto a cada identidad, origina actos cognitivos y políticos violentos (Arisó y Medina, 2010), que viene de lejos y pervive en nuestros días en varios países y con similar contundencia. Aquí el estudio se ciñe a la lengua española, con ejemplos de varios países por su empleo plurinacional, si bien predominan las ilustraciones de México para algunos temas, como el de las canciones.

Para empezar, una sucinta definición de lenguaje. Es una forma simbólica, un proceso de comunicación mediante el cual transmitimos información de sentimientos y pensamientos a través de imágenes o palabras que son creadas por las personas y éstas a su vez son construidas por aquellas (Ducrot y Todorov, 1984; Benveniste, 1984). En palabras de Robine Lakoff (1995:31) “El lenguaje nos utiliza tanto como lo utilizamos". Porta creencias que son planteamientos pre formados y pre organizados de percepción que filtran la comunicación intersubjetiva e intra psíquica. El lenguaje verbal en concreto es una de las formas más importantes para expresarse y comunicarse (Saussure, 1980), y no es neutro ni inocente, siendo utilizado desde los que tienen el poder (Barthes, 1980).

En resumen, el lenguaje es un molde y en su seno se nace a la cultura y a la vida en relación (García, 1982; Tannen, 1994), toda vez que refleja a la sociedad y la cultura de la que forma parte (Burke, 1996). Construye las maneras de entender e interpretar el mundo, trasmite conocimientos y experiencias. Refleja la realidad social, también como se señaló, la crea y produce (Violi, 1991). Enseña a pensar e incluso nombra sentimientos. Conforma el mundo y las relaciones y prácticas sociales, así como configura universos 
simbólicos e imaginarios culturales. Estructura subjetiva y culturalmente, y las personas a su vez construyen y nombran al mundo a través del lenguaje (Berger y Luckmann, 1986). Una relación bidireccional, donde está el poder (Foucault, 1991) y también el conflicto (Simmel, 2010), como el entendimiento y la comprensión (Rosenberg, 2010), de ahí el lenguaje no violento y para la paz, como se verá en su momento.

Para continuar una muy breve definición y esquema de la violencia en general y de género en particular, y más específicamente en el empleo del lenguaje. La violencia es "Daño ejercido sobre los seres humanos por parte de otros seres humanos" (Jiménez-Bautista, 2012:14). Mucho se ha discutido si la violencia es parte de la naturaleza humana o de la cultura, en la actualidad las ciencias sociales se decantan por lo segundo, y se añade que posee una gratuidad biológica e intencionalidad psicológica, además que no es innata se aprende. Siguiendo a Galtung, uno de los especialistas en el tema de la violencia, hay tres tipos: la directa, estructural y cultural. La primera es visible, ejercida directamente y tiene que ver con el comportamiento, físico, psicológico y verbal -esto último mediante el empleo del lenguaje-. La segunda no visible e indirecta tiene que ver con la negación de las necesidades -desigualdad, explotación, represión, etc.-. En cuanto a la tercera de la cual forma parte también el lenguaje, entre las ideas, normas, valores, religiones, ciencia, ideología, o arte, es invisible en ocasiones y se relaciona con actitudes, se usa para legitimar la primera y la segunda (Galtung, 2003). Así que la violencia en el lenguaje es su utilización clara y directa como acción en el habla (Austin, 1955; Searle, 2000), toda vez que su empleo justificatorio de otros tipos de violencia a través del discurso que es un acto social (Van Dijk, 2001). Al respecto Butler (2009) nos recuerda que algunas formas de habla transmiten odio e incluso hieren directamente. De Lauretis (1992) añade que la mujer es una construcción ficticia y un destilado de discursos. Ambas autoras consideran que los significados pueden ser modificados, y si las personas se construyen al pensar y hablar como afirma la primera, también pueden usar el lenguaje como resistencia y el habla puede ser subversiva advierten las dos.

Un breve recorrido sobre los estudios de género y el lenguaje, parte de Lakoff (1973) y la consideración del habla de las mujeres como débil y deficiente, esto desde la perspectiva hegemónica masculina. Un segundo acercamiento señala a las mujeres como grupo oprimido y subordinado a los hombres, las diferencias lingüísticas reflejan este dominio social y el ejercicio del poder a través del lenguaje (Zimmerman y West, 1975). El tercer enfoque apunta a subculturas de hombres y mujeres, y por tanto experiencias y expresiones distintas, lo cual no deviene en algo negativo. Los dos últimos enfoques, la dominación y la diferencia, se complementan según algunas estudiosas como Tannen (1994). Un cuarto acercamiento se centra en la construcción social y cómo las y los hablantes ejercen el género (Coates, 2009). Los diferentes enfoques no son excluyentes, pueden ser complementarios, por supuesto. En todo caso ya apuntan a la violencia de género en el lenguaje, y concretamente hacia las mujeres.

Hay que dejar claro desde un inicio que el lenguaje no es violento en sí, o no es sexista -adentrándonos al tema que convoca este artículo- lo es en concreto su uso (Gar- 
cía, 1994). Las palabras importan y el lenguaje nos moldea (Tannen, 1994), y lo que no se nombra no existe (Lledó, 2007). Dos primeros acercamientos al tema de la violencia hacia las mujeres tienen que ver con el sexismo en el lenguaje y con el androcentrismo lingüístico. El androcentrismo es "El hombre como medida de todas las cosas" (Sau, 1990) o "el arquetipo viril" (Moreno, 1986). La perspectiva y modelo del hombre como medida de todas las cosas, un mundo según su mirada, que excluye e invisibiliza a las mujeres. El androcentrismo lingüístico en concreto invisibiliza y excluye a las mujeres en el discurso, no las nombra o si lo hace no tienen un papel importante (Garí, 2006), desaparecen como personas, sus percepciones, perspectivas, experiencias no existen. Un ejemplo es la omisión del género gramatical femenino que sí existe en la lengua. Por su parte, el sexismo es una actitud de menosprecio y desvalorización hacia las mujeres y sus vivencias y miradas, sesgado el lenguaje por la hegemonía del poder de los hombres, con objeto de mantenerlas en "inferioridad, subordinación y explotación” (Sau, 1990). El sexismo lingüístico se basa en una visión plagada de imágenes, tópicos y estereotipos degradantes hacia las mujeres, además en ocasiones conlleva una crítica hacia ellas, siempre violencia de una u otra manera (Moreno, 1986; Sau, 1990; Garí, 2006; Lledó, 2006). En general, se utiliza léxico (palabras) o se construyen frases (sintaxis) de carácter discriminatorio (García, 1994).

Una vez realizadas algunas breves definiciones básicas al tema que nos ocupa, a continuación se presentan y describen ejemplos ilustrativos de la utilización de un lenguaje con violencia y discriminatorio hacia las mujeres en varios ámbitos, acompañados de algunas explicaciones y reflexiones. Se parte de que el lenguaje no es neutro, como se dijo -o por lo menos su empleo-, incorpora en su estructura la diferencia sexual y la transforma en dato natural, extra semántico, en estructura simbólica, dotada de significado y a la vez productora de sentido. Por un lado, quien habla deja su presencia subjetiva, y de otro la lengua inscribe y simboliza en su misma estructura la diferencia sexual de forma jerarquizada y orientada. La simbolización de esta diferencia en el lenguaje configura de antemano la estructura de los roles y estereotipos sexuales que son asimilados posteriormente por los que hablan y reproducidos en el uso lingüístico (Violi, 1991). Las objetivaciones de la vida cotidiana se inscriben en el lenguaje -acumulación de experiencias y significados- y se presentan como facticidad externa y con efecto coercitivo sobre las personas, particularmente las mujeres en este caso, y la sociedad en su conjunto (Berger y Luckmann, 1986).

\section{GÉNERO GRAMATICAL}

Son necesarios, pues, cambios en el lenguaje para nombrar a las mujeres; y, por lo tanto, debemos realizarlos: los prejuicios, la inercia, o el peso de las reglas gramaticales, que, por otra parte, siempre han sido susceptibles de cambios, no pueden ni deben impedirlo. En la lengua castellana existen términos y múltiples recursos para nombrar a hombres y mujeres. La lengua tiene la suficiente riqueza para que esto pueda hacerse adecuadamente (Alario, Bengoechea, Lledó, Vargas, 1995:9). 
Un ejemplo de lo anterior es el género gramatical en ocasiones diferenciado, existente, y sin embargo, no utilizado, sobre esto trata este apartado. En el lenguaje la diferencia sexual está simbolizada principalmente a través de la categoría lingüística de género gramatical, que no sólo regula hechos concordantes de forma mecánica -como afirman los especialistas en la materia-, sino que es una categoría semántica que manifiesta en la lengua un simbolismo profundo ligado principalmente al cuerpo y a la diferencia sexual. Es importante destacar que primero es la oposición en la naturaleza, luego la inversión simbólica -prelingüística y emocional de valores conectados al simbolismo sexual- y finalmente la forma lingüística -orden contrario al que afirman algunos lingüistas-(Violi, 1991).

En este sentido aparece el mencionado androcentrismo, que conforma una perspectiva: la mirada masculina como centro de todas las cosas, excluyendo e invisibilizando a las mujeres (Sau, 1990). Las mujeres no son consideradas, no son vistas, no son oídas, no son reconocidas y no son nombradas; es la exclusión e invisibilización de las mujeres, esto es, ni mencionarlas. Los ejemplos son innumerables, tomamos algunos de libros de texto, periódicos y habla cotidiana.

\author{
El hombre habita el planeta tierra \\ Los hombres crearon la cultura \\ El hombre inventó la agricultura ${ }^{1}$ \\ El lenguaje es fruto del hombre ${ }^{2}$ \\ En el accidente fallecieron diez campesinos \\ Día del niño \\ Los maestros enseñan bien ${ }^{3}$
}

En la lengua española el género gramatical puede ser femenino, masculino y neutro. El femenino lo componen sustantivos que significan personas o animales de sexo femenino, y también nombres de seres inanimados; en concordancia con los sustantivos hay artículos, pronombres, adjetivos y determinantes varios. Por lo cual el uso del femenino gramatical es totalmente posible y dentro de la normativa lingüística existente.

Por otra parte, no es tampoco del todo correcto el considerar que el uso del femenino y masculino atenta contra la economía del lenguaje, ya que y para empezar, no todo el lenguaje se caracteriza por su economía como, por ejemplo, un coloquio literario o un ensayo filosófico. Por lo que emplear ambos géneros gramaticales no debiera ser problema, además podemos usar los genéricos o abstractos u otras posibilidades alternativas que incluyen ambos sexos si de ahorrar palabras se trata y que son recursos con los que la lengua ya cuenta.

1 Cuando ya se ha estudiado desde la historia y la antropología que en general y para este tema fue la mujer (Harris y Young, 1979).

2 Aunque se acusa a las mujeres de usarlo en demasía (Fernández, 2002a).

3 Cuando la mayoría son maestras, especialmente de primaria (González, 2009).. 
Argumento muy esgrimido, el de la economía del lenguaje, que por supuesto es real, y que utiliza la Academia de la Lengua Española con objeto de frenar el utilizar el femenino y masculino cuando sea el caso. Sin embargo, no es menos cierto que la no utilización del masculino y femenino cuando corresponde, tergiversa, oculta, excluye, cuando no confunde, como y también borra la diversidad de opciones que se tienen. Alternativas hay, por ejemplo: "Los ciudadanos votaron por la paz" puede ser cambiado por "Los ciudadanos y las ciudadanas", "Las y los ciudadanos", "Los y las ciudadanas", "Las/os ciudadanas/os", "Los/as ciudadanos/as", "La ciudadanía", "La población con derecho al voto", "Las personas que sufragan".

Además, en las expresiones hay que ir cambiando los tópicos sexistas, por ejemplo en las profesiones, "los médicos y las enfermeras"; y como el "señor" versus "señora" y "señorita"; o también como "Juan Pérez y Anita", por poner solo unas pocas ilustraciones del fenómeno.

Remarcar finalmente que como ya se dijo, la diferencia sexual existe, no la crea el lenguaje, lo que este hace es reflejarla si lo hace u ocultarla en caso contrario. ¿Qué elegimos nosotros/as al hablar o escribir? Ahí está el detalle.

\section{LÉXICO Y ESTEREOTIPOS}

La resignificación del lenguaje requiere abrir nuevos contextos, hablando de maneras que aún no han sido legitimadas, y por lo tanto, produciendo nuevas y futuras formas de legitimación (Butler, 2004:73).

Esto es una apuesta al cambio, que por ejemplo, parece necesario a juzgar por la discriminación que se observa en este apartado sobre el léxico. El sexismo es una actitud: de menosprecio y desvalorización hacia las mujeres y sus pensamientos o actos, su mundo en general (Sau 1990), como ya se dijo ${ }^{4}$. El sexismo lingüístico es la imagen femenina hecha palabra, descalificada, infravalorada, subordinada o incluso denigrada o violentada, muchas veces fincada en estereotipos de carácter negativo. El sexismo lingüístico opera en los vocablos, esto es, sexismo léxico, y también en la construcción de oraciones, sexismo sintáctico, todo según lo expuesto con anterioridad. A continuación ejemplos de esto desde el habla en general y los refranes en particular, los cuales más adelante focalizarán la atención en estas páginas.

La mujer como la escopeta, cargada y en un rincón

La esposa del gobernador es bella, elegante y simpática

4 Por supuesto, también hay sexismo hacia los hombres, cuando por ejemplo, se los asigna el mandato exclusivo como proveedores, entre otras cosas (Fernández, 2002a). 
En 1953 se otorgó el voto a las mujeres en México 5

Las mujeres no se enojan

Los estereotipos sobresalen en el léxico cotidiano del habla coloquial. Se trata de una suerte de preconcepción generalizada, que simplifica la percepción, la organiza, así como el proceso mental y el entendimiento, como economía del lenguaje que es, a la hora de conocer la sociedad. Por lo tanto, deviene en construcciones y generalizaciones, categoriza la cognición y origina tradiciones culturales dominantes, creencias exageradas que legitiman ciertas actitudes, conductas e incluso la misma discriminación (Allport, 1968; Huici, 1996; Lippmann, 2003). A veces se fundan en diferencias biológicas, otras en conductas sexuales o roles sociales, igual que en las diferencias intergenéricas que derivan en muchas ocasiones en discriminación directamente, como se dijo, a veces incluso en estigma social.

En particular los estereotipos de género, son las diferencias construidas a partir del sexo por adjudicación social que devienen en ideas, sentimientos, normas y valores históricamente construidos con una caracterización física y psicológica. En la sociedad las mujeres estereotipadas como grupo en general son desvalorizadas como colectivo y persona en particular, etiquetadas según imágenes mentales y en perjuicio de su autoestima (Santoro, 1969; González, 1999; Cook y Cusack, 2011). A lo cual es posible añadir el rol o papel social, o sea, el deber ser, como conjunto de normas y funciones, expectativas y conductas supuestamente apropiadas que marcan las relaciones interpersonales y reproducen la socialización de cierto comportamiento, definidas culturalmente y reproducidas socialmente (Sarbín, 1975; Turner, 1975). Por lo que el rol sexual o de género es la adjudicación según sexo de determinadas funciones, tareas y conductas que se desarrollan normativamente según los estereotipos de género y lo esperado sobre los mismos.

El léxico, los estereotipos y roles recorren el lenguaje oral y escrito, así como las mismas palabras. Tal es el caso de la definición de mujer y de hombre en los diccionarios, sin ir más lejos, su significado e incluso extensión de las mismas como en el Diccionario de la Lengua de la Academia Española de la Lengua, especialmente en versiones de hace pocos años, o los descalificativos hacia las mujeres al ser asimiladas a ciertos animales, o los insultos a ellas dirigidos en lo que se conoce como los "duales aparentes" (García, 1994), desde "hombre público" a "mujer pública", hasta "perro" y "perra" o "gallo" y "gallina" (Sau, 1990).

Además de las típicas frases que se emplean a menudo en el habla cotidiana "hombres inteligentes y valientes" y "mujeres bellas y amorosas", calificativos o descalificativos en su caso, que conllevan sesgos de género importantes atravesando la cultura, la mente y el lenguaje.

5 En vez de decir se ganó, logró, reconoció, consiguió u obtuvo, no obstante, dicha afirmación aparece a menudo en estudios sobre mujeres y política de académicas, ignorando las luchas sufragistas desde finales del siglo XIX o las movilizaciones de los años 30 del siglo XX, entre otras cosas, en el caso particular mexicano. 
Caso especial es el uso de la palabra madre, ya que oscila desde lo más bueno "a toda madre" o "de poca madre", a lo más malo "me vale madres", "hasta la madre" o "chinga tu madre", hasta algo que ni existe o es cualquier cosa sin importancia "es una madre". 6

Otro ejemplo es la palabra "vieja" que en refranes es objeto de burla especial por la pérdida de la belleza o por su asociación con el diablo. Y en los chistes se subraya la diminución de habilidades y de los sentidos, entre otras cosas. Aquí ejemplos de antiguos refraneros y de chistes relatados en nuestros días. Sobre estas narrativas nos explayaremos en el apartado siguiente.

Vejez y hermosura, nunca se vieron juntas

Vieja y fea, que el diablo la quiera

Escucha a los grillos. No son los huesos de Paulina

¿Estás gorda? Sí como una tapia

\section{NARRATIVAS POPULARES}

Hombres y mujeres aprenden a serlo a través de la lengua, hablando y oyendo hablar. Al utilizar la lengua como han visto y oído, niñas y niños mantienen y perpetúan el sexismo, la subordinación femenina y la transmisión de valores androcéntricos (Bengoechea, 1995:4).

De ahí la importancia del lenguaje que estructura percepciones, sensaciones, pensamientos, emociones, actitudes, comportamientos, formas de actuar, de ser y estar en el mundo. A continuación se presenta el discurso y los mensajes de género y la violencia hacia las mujeres a través de cuatro narrativas tradicionales y populares: canciones, refranes, chistes y acertijos. Las fuentes de las cuales proceden las mismas son básicamente el habla cotidiana en algunos casos, y en obras tales como refraneros o cancioneros, además de libros que abordan algunos temas de forma específica (Fernández, 2002a; 2002b).

\section{Aproximaciones a las canciones}

Las letras de algunas canciones transportan mensajes dentro de cierto discurso tradicional por denominarlo de alguna manera, se cantan, bailan y celebran, no siempre escuchando conscientemente sus letras. Un lenguaje que transporta significados, que crea y estructura el pensamiento, reproduce cierta ideología y la perpetúa en la sociedad y en la cultura. La lengua como sistema de comunicación en un sistema social, instrumento de objetivación y legitimación (Berger y Luckmann, 1986; Ricci y Zani, 1990), todo en el sentido que ya se expuso en los anteriores apartados. En fin, letras de canciones donde

6 Para el caso de México y algunos otros países. 
muestran a las mujeres, malas, objeto de maltrato e incluso justificación de su muerte. Mujeres denigradas y violentadas verbal y simbólicamente (Bourdieu, 2000), herencia androcéntrica y sexista que discrimina a las mujeres y modela el maltrato hacia las mismas, parte del discurso cultural sexuado hegemónico en melodías populares.

En el caso de parte de la canción popular mexicana las mujeres son por excelencia malvadas, infieles en los romances, traicioneras en los corridos y la canción romántica, ingratas en las rancheras. Sus errores y faltas, así como, la no correspondencia a una insinuación o declaración de amor, su infidelidad o deshonor, merece castigo, desprecio, sufrimiento, incluso hasta la misma muerte.

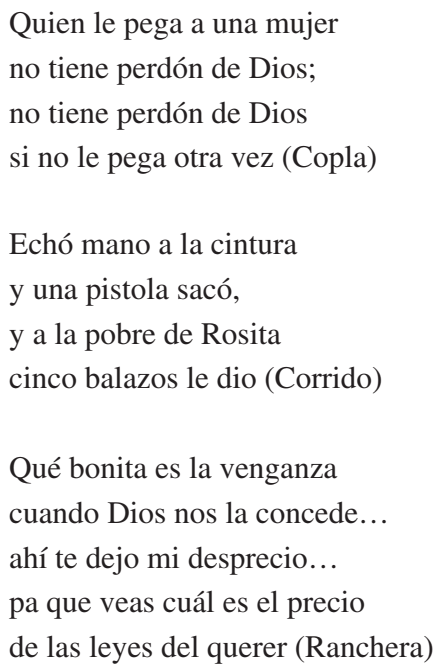

Además, en la canción infantil que se sigue entonando aparece este mensaje tradicional que reproduce los roles y estereotipos de género de forma clara y directa.

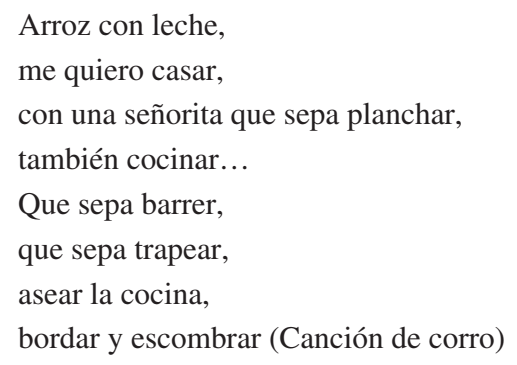

La reproducción del orden social hegemónico tiene lugar, quizás se diga que en menor medida o en menos lugares o en ciertas generaciones, no obstante, sí hay resistencia y permanencia. Ello en el sentido que ha habido cambios legislativos, políticos, discursivos plasmados en acciones institucionales, fomento en los medios de comunicación y aplica- 
ción de políticas públicas, pero y pese al reconocimiento anterior al parecer falta bastante por hacer a juzgar, por ejemplo, por los casos de violencia hacia las mujeres que tienen lugar en varios países del mundo.

\section{Un acercamiento a los refranes}

El refrán es una narrativa popular, un discurso didáctico moral y lapidario, con mensajes en general conservadores y discriminatorios, una de cuyas protagonistas es la mujer, desde una mirada sexista, por supuesto. Uno de los temas además en los que destaca la mujer es su habla. Con lo cual aquí se junta la revisión del refrán sexista y se concreta en una temática relacionada con el lenguaje, se muestra con ejemplos que existen en diversos países latinoamericanos al compartir una misma lengua, aunque con sus diferentes variables y versiones.

$\mathrm{Ni}$ al perro que mear, ni a la mujer que hablar, nunca les ha de faltar

Donde hay barbas, callen faldas

A lavar al río fui, mal dije de otras y peor dijeron de mí

Truchas y mujeres, por la boca se pierden

La mujer y el horno, por la boca se calientan

Mujer y perra, la que calla es buena

Antes se queda el ruiseñor sin canción que la mujer sin conversación

Por otra parte, y al lado del menoscabo directo del habla excesiva de las mujeres, existen otras críticas relacionadas con la descalificación del comportamiento socio lingüístico, pues además de charlatanas, se las considera mentirosas, incoherentes, desordenadas, contradictorias e indiscretas. Ejemplos estos que se seleccionan por lo dicho, la relación entre mujeres y lenguaje, su locuacidad y engaño, como características del habla femenina.

La mujer y la mentira nacieron el mismo día

Mujer que no mienta ¿quién la encuentra?

En cojera de perro y lágrimas de mujer no hay que creer

Entre el sí y el no de una mujer, no cabe la punta de un alfiler

Mujeres y fortuna, mudables como la luna

Febrero y las mujeres, por día diez pareceres

Mujer, niño y loco no guardan secreto de otro

Llegados a este punto, parece importante recordar y resaltar el papel del lenguaje y la violencia que transporta, su uso no es neutro, incorpora y transforma la diferencia sexual en estructura simbólica, productora y reproductora de sentido. De una parte, el o la hablante deja su presencia subjetiva, de otra la lengua inscribe y simboliza en su misma estructura la diferencia sexual de manera orientada y jerarquizada. La simbolización de 
esta diferencia en el lenguaje configura de antemano la estructura de los roles sexuales que son asimilados posteriormente por los que hablan y reproducidos en el uso lingüístico (Violi, 1991), así las objetivaciones de la cotidianeidad se imprimen en el lenguaje -acumulación de vivencias y significados- y se muestran con facticidad externa de carácter coercitivo sobre las personas individuales y a la colectividad en su conjunto (Berger y Luckmann, 1986). El lenguaje, como se dijo, es un acto social y con las palabras se hacen cosas (Austin, 1955; Searle, 2000; Van Dijk, 2001).

Añadimos algunos refranes más, ilustrativos de una gran violencia y crueldad, y si bien el refranero quizás no es tan empleado como antaño, ciertamente sí hay lugares donde todavía permanece y se reproduce su eco.

Las mujeres son un mal necesario

La mujer es el piojo del hombre

A la mujer y a la burra, cada día una zurra

A la mujer y a la carne, mientras chillen, darle

De la dureza lapidaria y conservadora del refranero pasamos a la ligereza y carácter lúdico del chiste, no por ello menos sexista y discriminatorio, como se verá.

\section{Algo sobre los chistes}

Prosiguiendo con las narrativas populares, se pueden abordar los chistes algo más contemporáneos y prolíficos en nuestros días que señalan mucho de la conducta de las mujeres, y también en este caso concreto de los hombres, ya que tanto ellas como ellos son criticados, objeto de burla, discriminados y violentados de forma y en cantidad similar. Se aborda el tema del habla de las mujeres para continuar lo iniciado con los refranes y porque es parte del lenguaje violento, objeto de estudio de este texto. Aquí el señalamiento es similar al refranero, no obstante, por su carácter lúdico, parece menos agresivo, incluso chistoso, no por ello menos violento en cuanto al contenido, como ya se dijo.

Una mujer plantea una demanda de divorcio arguyendo que su marido no le ha dirigido la palabra en dos años. El juez le pregunta al marido: ¿por qué no le ha hablado a su mujer en dos años? A lo que responde: No quería interrumpirla.

Me dijeron que usted es un hombre que domina muchas lenguas. Efectivamente domino todas menos una. ¿Cuál? La de mi esposa.

¿Por qué Dios hizo antes a Adán que a Eva? Para darle una oportunidad de hablar.

¿Por qué Dios creó al hombre antes que a la mujer? Porque quería que nadie le estuviera diciendo cómo hacer las cosas.

Eso sí, hay chistes de muchas temáticas, de los ligeros y pícaros hasta los hostiles y crueles, y como se mencinó de un sexo hacia el otro, a veces incluso indistintamente, o 
chistes iguales donde solo se cambia el sexo del atacado y atacante. Si bien en ocasiones parecen chistes contra mujeres, algunos entre líneas y más allá de la crítica hacia estas, también contienen cierta actitud a la defensiva, esto es, se las ataca o se burla de ellas, porque se reconoce cierto poder, contrariamente a lo esperado tras anteriormente revisar el refranero. En la narrativa anterior se ha de interpretar y analizar desde la psicología social, en esta basta leer entrelíneas el guiño emitido.

La esposa le dice al marido: -¿Por qué no viniste anoche a casa? -Es que perdí las llaves y no quise molestarte. - ¿Con que perdiste las llaves, eh? -Sí. ¿Te encontraste muy sola? -No. Afortunadamente otro señor las encontró

Añadir que algunos chistes violentos poseen un carácter sumamente duro, aquí se muestran varios.

¿Qué entienden los hombres por ayudar con el quehacer?

Levantar el pie para que puedas pasar la aspiradora

¡Cuáles son los tres tipos de mujeres que existen? Uno: las fieles; son las que lo hacen solamente con vos. Dos: las putas; las que lo hacen con todo mundo hasta con vos. Tres: las hijas de puta; las que lo hacen con todo mundo menos con vos

¿Cuándo pierde una mujer el $90 \%$ de su inteligencia?- Cuando se queda viuda. ¿Y el otro $10 \%$ ? Cuando se le muere el perro

Y para ir finalizando el texto se presentan algunos acertijos cuya narrativa nos invita a la reflexión, no solo en torno al uso del lenguaje sexista, sino a cómo el sexismo ha cristalizado en nuestra mente y nuestra cultura, nos construye y estructura, lo cual se ha expuesto con citas de autoras y obras, y aquí lo señala en el fraseo simple, aunque indirecto, de los acertijos.

\section{Finalización con acertijos}

Concluimos este apartado de narraciones populares y tradicionales con un ejercicio que puede realizar el lector y la lectora del mismo, y que incluso puede ser un examen final sobre la sensibilidad hacia el tema abordado a lo largo de estas páginas. Se trata de un acertijo, en diferentes versiones que como todos se ha de adivinar.

El señor Hernández y su hijo Gonzalo iban en su coche. Tuvieron un accidente. El padre murió en el acto y el hijo quedó herido de gravedad y lo ingresaron en el hospital. Al verlo, el jefe del departamento de cirugía dijo: "Yo no lo puedo operar ¡Si es mi hijo Gonzalo!"

Pérez tenía un hermano. El hermano de Pérez murió. Sin embargo, el hombre que murió nunca tuvo un hermano 
García vivía con su padre, pero el padre de García murió; sin embargo, el padre de García nunca tuvo un hijo ni vivió con él

Dos indios americanos, uno niño y otro adulto, están sentados en un tronco, el niño indio es hijo del adulto, pero el adulto no es el padre del pequeño

Dos esquimales fueron a pescar: El menor era hijo de mayor, pero el mayor no era el padre

Si has adivinado felicidades, en caso contrario también felicidades pues estamos imbuidos del género gramatical, el léxico y las narrativas populares androcéntricas y sexistas así que estamos en la media, pero eso sí con la posibilidad de trascenderla y salir de ella como se verá en el punto de las conclusiones. Estas narrativas populares mostradas de forma breve son una pincelada de la dominación de hombres hacia mujeres o de un discurso hegemónico que permaneció durante centurias y que hoy si bien está cambiando, no siempre tan rápido ni ampliamente como se desearía o cabría suponer, hay resistencias persistentes, no obstante, como sabemos lo único permanente es la impermanencia.

\section{CONCLUSIONES Y REFLEXIONES}

“Podría el lenguaje herirnos si no fuéramos, en algún sentido, seres lingüísticos, seres que necesitan del lenguaje para existir" (Butler, 2004:16). Un lenguaje que como se ha dicho y aquí se retomará, nos crea y recrea, estructura y desestructura, nos construye toda vez que lo construimos, de ahí el poder de resignificar, evitar, cambiar, mismo que se desea reiterar en este punto.

En este texto se ha pasado revista a reglas morfológicas y gramaticales, léxico y construcción de significados, así como, discursos y mensajes que discriminan y menosprecian, invisibilizan o insultan, en relatos y expresiones populares. Parte de la violencia simbólica que existe y persiste hacia las mujeres (Bourdieu, 2000). No obstante, todo se puede resignificar y cambiar (Butler, 2009), como se acaba de mencionar, más en algo vivo como la lengua que es fruto de la construcción humana en el devenir de la sociedad y la historia.

Para ir concluyendo es conveniente dejar claro que la diferencia sexual existe (Alario, Bengoechea, Lledó, Vargas, 1995), nombrarla es lo lógico y razonable, además de éticamente recomendable, no hacerlo se debe al peso de la tradición, y mencionarla a veces de manera discriminatoria también es fruto de la fuerza de la costumbre. Quizás inconscientemente y sin darnos cuenta, tal vez porque se cree en la espontaneidad y en la economía del lenguaje es que el androcentrismo y sexismo lingüístico se mantienen. En todo caso, parece claro que la violencia de género en general se inscribe en el espacio de los comportamientos corporales y también en los esquemas perceptivos y su expresión, tiene lugar en el orden simbólico (Bourdieu, 2000) y a través de la discriminación en el 
lenguaje (Violi, 1991). Todo lo cual redunda en dominación y violencia emocional, cultural, simbólica y lingüística hacia la población femenina entre otras inequidades sociales que también existen.

Varias investigadoras señalan la necesidad de cambios en el lenguaje para nombrar a las mujeres, incluso aduciendo la riqueza de la lengua para adecuarse a los nuevos tiempos (Alario, Bengoechea, Lledó, Vargas, 1995); y cuando la gramática no lo permite también es posible cambiarla.

Llegados a este punto se quiere realizar una reflexión de carácter práctico en torno a las posibilidades de la lengua para evitar el androcentrismo y sexismo lingüístico que se espera haber dejado claro a lo largo de estas páginas. La reproducción de la violencia persiste a pesar de las nuevas ideas, leyes y las campañas de equidad, el darse cuenta, sensibilizarse, emplear un lenguaje no violento es parte de una nueva ética que se está construyendo. Hay lenguajes violentos y hay lenguajes no violentos. El primero desvaloriza, niega, oculta, juzga y condena; el segundo, respeta, valora, escucha, comprende, reconoce, comparte o no ideas, expresa necesidades (Filliozat, 2007).

Ahora tras resumir el panorama esbozado en el texto, hay que preguntarse ¿qué hace la violencia? Y ¿qué hacer con la violencia? Esto es, reflexiones y propuestas para el presente y el futuro.

\section{¿Qué hace la violencia?}

La violencia en el lenguaje parece ser parte de la cultura, de la mente individual y del inconsciente colectivo. Creencias y emociones expresadas en gramática, palabras, frases o relatos que ocultan, desconocen, denigran e insultan, en este caso a las mujeres. Pero a la hora de expresarse ¿qué es lo que se hace? Por un lado, es obvio que reproduce el orden social establecido, en este caso la dominación masculina (Bourdieu, 2000). Por otro lado, también es posible ver como libera de alguna manera o en alguna medida, ya que expresa y descarga tensión. Se trata de una violencia que refleja la violencia social, que como acto que el lenguaje es, la reitera también, toda vez que al expresarse libera energía, alivia física y psicológicamente (Freud, 2008) y quizás se suaviza y relativiza desde la mente, las emociones y el cuerpo, y la cultura o incluso se aplaza o evita el llegar a otros tipos de violencia directa. Comprender esto es importante, aunque por supuesto no sea el objetivo de este trabajo. Entender la fuerza de la palabra, el poder de la expresión, también para liberar, toda vez que se reproduce el orden de las cosas y la violencia. De hecho, son síntomas sociales que es posible descifrar y así poder actuar para transformar la sociedad que origina dichas expresiones lingüísticas.

Por otra parte, recordemos que el discurso es un acto social (Van Dijk, 2001) y las palabras con actos sociales (Austin, 1955; Searle, 2000) y el lenguaje hiere (Butler, 2004), además de ser un instrumento de socialización potente en todos los espacios sociales (Berger y Luckmann, 1986); así la violencia en el lenguaje adoctrina. Y si la violencia se aprende, el camino contrario también se puede recorrer, esto es, desaprender y cambiar 
la cultura de la violencia por una cultura de paz. En todo caso, el verla en el lenguaje nos sirve para darnos cuenta de que detrás de ella hay un conflicto no resuelto, o mejor dicho no transitado (Galtung, 2003), por lo que el solo hecho de pronunciarla y escucharla, es una oportunidad para hacer consciencia sobre el tema.

\section{¿Qué hacer con la violencia?}

Combatir no lleva a ninguna parte, lo que se resiste persiste, si atacas hay contraataque, y así se reproduce la violencia de forma infinita. Lo posible es crear conciencia de la existencia de este tipo de expresiones lingüísticas violentas y dolorosas, y evitarlas, no ejercerlas, corregirlas o abstenerse de pronunciarlas, esto es, no participar en su reproducción, corregirla si es el caso. Se precisa construir relaciones respetuosas entre las personas, ético-políticas, un nuevo pacto social para eliminar las formas violentas que transforman la diferencia en desigualdad (Arisó y Medina, 2010).

Una solución es la educación y en paralelo la concientización, desde el darse cuenta simple e inmediatamente hasta la reflexión más amplia y profunda que elige no reproducir los mensajes sexistas de la violencia directa y cultural, lingüística y simbólica. Si la violencia se aprende -la familia, la escuela, y hoy en día los medios de toda índole-, también puede desaprenderse por medio de la conciencia en unos y una educación para la paz. Educación, campañas, leyes, políticas públicas, y mucha concientización.

La propuesta de Galtung es que las culturas y estructuras violentas no se pueden solucionar mediante la violencia, pues ello conduce a nuevas estructuras y culturas violentas. Por lo que esta se remontará a través de una cultura y una estructura de paz con los medios necesarios para transitar conflictos. Y ¿Cómo transformar el conflicto por medios pacíficos? A través de empatía, creatividad y no violencia. Si quieres paz prepárate para la paz (Galtung, 2003), la paz se obtiene por medios pacíficos, puede ser enseñada y aprendida. Galtung (1998) propone la reconstrucción y reconciliación tras la violencia, y sobre todo la transformación de los conflictos que están en la base de la misma. En el caso estudiado es claro que se trata del conflicto intergenérico y al solucionarse el mismo, su reflejo y recreación lingüística también desaparecerán pues carecerán de sentido.

Un acercamiento a la comunicación no violenta es la de Rosenberg (2010), que señala que las palabras pueden llegar a ofender y herir a las personas e incluso a quien las emite, pero se puede reestructurar la forma de expresión, partiendo del no juzgar, observar sin evaluar, no comparar y ser responsable de los sentimientos. Propugna la atención empática y respetuosa, la escucha atenta y profunda, así como, descartar las reacciones habituales automáticas y sustituirlas por palabras de respeto consciente. La base está en el observar qué hace y dice el otro y la otra, y cómo me siento yo con eso, y expresar nuestras necesidades con relación a la otra y al otro, o a nuestros sentimientos, de la forma más clara, directa y equilibrada posible. Lo cual es aplicable a las relaciones de género, y aconsejable en pos de evitar la violencia lingüística hacia las mujeres y sustituirla por valoración y respeto. 
Junto a la retirada en cuanto a la utilización del androcentrismo y sexismo en el lenguaje que violenta a las mujeres, se puede trabajar para promover un lenguaje más pacífico y no violento.

El lenguaje es imprescindible para neutralizar la violencia cultural. Primero, utilizándolo apropiadamente, dando el significado exacto a cada término que utilizamos; segundo, ir eliminando poco a poco los términos con elevada significación de violencia $\mathrm{y}$, tercero, añadir otros valores positivos implícitos en el lenguaje, y en lo referente al trato entre personas, clase social, género, etnia, etcétera, cada una con sus distintas lenguas donde debamos utilizar un lenguaje neutral (Jiménez-Bautista, 2012:41). ${ }^{7}$

La gramática, las palabras, los mensajes son expresión lingüística y cultural, emocional y energética; crean, recrean y transforman socialmente; mueven y conmueven personalmente, en especial cuando conllevan violencia verbal y en particular las ocultaciones, las desvalorizaciones y los insultos. Estaría bien observar las palabras que escuchamos y también antes de proferir palabra alguna preguntarnos para qué sirve lo que voy a decir, si es útil, y qué objetivo tienen mis palabras, además de pensar cómo lo voy a decir, si es de forma apropiada o no. Y si ya las he expresado por el automatismo de nuestra mente-palabra, revisarlas y no culpabilizarnos, hacernos responsables de las mismas y aprender a pensar antes de hablar, porque como dice el sabio refrán "una es dueña de lo que calla y esclava de lo que dice" y otro dicho más sabio todavía "madurar es cuidar lo que dices, respetar lo que escuchas y meditar lo que callas".

$7 \quad$ Curioso como los textos que predican la no violencia y la cultura de la paz utilizan todavía términos muy violentos, como los que hablan de utilizar un lenguaje equitativo todavía lo hacen desde el masculino singular. Pero eso solo comprueba que estamos en una época de transición, donde las cosas están cambiando, convivimos con los resabios del discurso del pasado y el nuevo paradigma y nuevas prácticas que todavía no se acaban de instaurar. 


\section{BIBLIOGRAFÍA}

Alario, C., Mercedes B., Lledó, E. y Vargas, A. (1995): Nombra. La representación de femenino y el masculino en el lenguaje. Madrid, Instituto de la Mujer.

Allport, G.W. (1968): La naturaleza del prejuicio. Buenos Aires, Eudeba.

Austin, J. (1955): Como hacer cosas con las palabras: palabras y acciones. Edición Electrónica de www.philosophia.cl. Recuperado de: http://revistaliterariakatharsis. org/Como_hacer_cosas_con_palabras.pdf

Barthes, R. (1980): Mitologías. Madrid, Siglo XXI.

Bengoechea, M. (1995): "El sexismo en el discurso", Mujeres,18, pp. 4-5. Madrid, Instituto de la Mujer.

Berger, P. y Luckmann, T. (1986): La construcción social de la realidad. Buenos Aires, Amorrortu.

Bourdieu, P. (2000): La dominación masculina. Barcelona, Anagrama.

Burke, P. (1996): Hablar y callar. Funciones sociales del lenguaje a través de la historia. Barcelona, Gedisa.

Butler, J. (2004): Lenguaje, poder e identidad. Madrid, Síntesis.

Coates, J. (2009): Mujeres, hombres y lenguaje. Un acercamiento sociolingüístico a las diferencias de género. México, FCE.

Cook, R. y Cusack, S. (2011): Estereotipos de Género. Perspectivas Legales Transnacionales. Bogotá, Profamilia.

De Lauretis, T. (1992): Alicia ya no. Feminismo, Semiótica, Cine. Madrid, Cátedra.

Ducrot, O, y Tzvetan, T. (1984): Diccionario enciclopédico de las ciencias del lenguaje. México, Siglo XXI.

Fernández, A. M. (2002a): Estereotipos y roles de género en el refranero popular. Charlatanas, mentirosas, malvadas y peligrosas. Proveedores, maltratadores, machos y cornudos. Barcelona, Antrhopos.

Fernández, A. M. (2002b): Pero vas a estar muy triste y así te vas a quedar. Mensajes de género en la canción popular mexicana. México, INAH.

Filliozat, I. (1991): El corazón tiene sus razones. Conocer el lenguaje de las emociones. Barcelona, Urano.

Foucault, M. (1991): Historia de la sexualidad 1. La voluntad de saber. México, Siglo XXI.

Freud, S. (2008): El chiste y su relación con lo inconsciente. Madrid, Alianza Editorial.

Galtung, J. (1998): Tras la violencia 3D: reconstrucción, reconciliación, resolución. Afrontando los efectos visibles e invisibles de la guerra y la violencia. Bilbao, Guernika Gogoratuz,

Galtung, J. (2003): Paz por medios pacíficos. Paz y conflicto, desarrollo y civilización. Bilbao, Guernika Gogoratu. 
García, A. (1982): "El lenguaje y los sexos", pp. 80-90, en Folguera, P. (coord.), Perspectivas sobre la mujer. Actas de las primeras jornadas de investigación interdisciplinaria. Vol. 2. Madrid, UAM.

García, A. (1994): ¿Es sexista la lengua española? Una investigación sobre el género gramatical. Barcelona, Paidós.

García, P. (2003): Así hablan las mujeres. Curiosidades y tópicos del uso femenino del lenguaje. Madrid, La esfera de los libros.

Garí A. (2006): Hablamos de salud. Madrid, Instituto de la Mujer.

González, B. (1999): “Los estereotipos como factor de socialización de género", Сотиnicar, 12, pp. 79-88. https://doi.org/10.3916/c12-1999-12

González, R. M. (2009): “De cómo y por qué las maestras llegaron a ser la mayoría en las escuelas primarias de México DF”, Revista Mexicana de Investigación Educativa, 14 (42), pp. 747-789.

Harris, O.; Young, K. (Coords.) (1979): Antropología y feminismo. Anagrama, Barcelona.

Huici, C. (1996): "Estereotipos", pp. 333-358, en Morales, F. J. y Huici, C. (coords.), Psicología social. Madrid. McGraw-Hill.

Jiménez F. (2012): “Conocer para comprender la violencia: origen, causas y realidad", Convergencia, 58, pp. 13-52.

Lakoff, R. (1973): El lenguaje y el lugar de la mujer. Madrid, Hacer.

Lippmann, W. (2003): La Opinión pública. Madrid, Lagre.

Lledó E. (2006): Las profesiones de la A a la Z. Madrid, Instituto de la Mujer.

Lledó E. (2007): De llengua, diferència i context. Barcelona, Institut Català de les Dones. Moore, H. L. (1991): Antropología y feminismo. Madrid, Cátedra.

Moreno, A. (1986): El arquetipo viril protagonista de la historia. Ejercicios de lectura no-androcéntrica. Barcelona, La Sal.

Ricci, P. E., Zani, B. (1990): La comunicación como proceso social. México, GrijalboCONACULTA.

Rosenberg, M. (2006): Comunicación no violenta. Un lenguaje de vida. Buenos Aires, Gran Aldea Editores.

Santoro, E. (1969): La televisión venezolana y la formación de estereotipos en el niño. Caracas, EBVC.

Sarbin, T. (1975): "Papel social", pp. 445-559, en Enciclopedia Internacional de las Ciencias Sociales. Bilbao, Aguilar.

Sau, V. (1990): Diccionario ideológico feminista. Barcelona, Icària.

Saussure, F. (1980): Curso de lingüística general. México, Fontamara.

Searle, J. (2000): Actos de habla. Madrid, Cátedra.

Tannen, D. (1994): Gender and Discourse. Oxford New York, Oxford University Press.

Turner, R. (1975): "Papel social”,pp. 559-564, en Enciclopedia Internacional de las Ciencias Sociales. Bilbao, Aguilar.

Van Dijk, T. (2001): "El discurso como interacción en la sociedad", pp. 19-66, en Van Dijk, T. A. (comp.), El discurso como interacción social. Barcelona, Gedisa. 
Violi, P. (1991): El infinito singular. Madrid, Cátedra.

Wittgenstein, L. (1988): Investigaciones filosóficas. Barcelona, Crítica.

Zimmerman, D.H., West, C. (1975): "Sex roles, interruptions and silences in conversation”, pp. 105-129, in Thorne, B., Henley, N. (eds.), Language and Sex: Difference and Dominance. Rowley, Newbury House. 